\title{
Metallocene to Metallocene Conversion. Synthesis of an Oxazoline- Substituted Pentamethyliridocenium Cation from a Ferrocenyloxazoline
}

\author{
Ross A. Arthurs, Peter N. Horton, Simon J. Coles and Christopher J. Richards*
}

Reaction of (S)-2-ferrocenyl-4-(1-methylethyl)oxazoline with [Cp*IrCl2]2 in benzonitrile with KPF6 and $\mathrm{NaOH}$ gave ( $\eta 5-(\mathrm{S})-2-(4-(1-m e t h y l e t h y l))$ oxazolinylcyclopentadienyl)( $\eta 5-$ pentamethylcyclopentadienyl)iridium(III) hexafluorophosphate (68\%). This transformation of an iron- based into an iridium-based metallocene proceeds via the rearrangement, with loss of cyclopentadienyliron, of an intermediate cationic ferrocenyliridacycle.

Metallocenes comprise one of the most important class of compounds in organometallic chemistry. Many catalysts and ligands are based on these complexes that contain an element, usually a transition metal, sandwiched between two $\eta 5$-cyclopentadienyl rings.1 Homoleptic metallocenes are made typically from the reaction of a cyclopentadiene or a cyclopentadienyl complex with a suitable metal precursor, 2 and these methodologies have been adapted widely to the synthesis of heteroleptic metallocenes. 3 The starting cyclopentadienyl complexes used generally contain an sblock element and are largely ionic in character, with examples including $\mathrm{CpLi}, \mathrm{CpNa}$ and $\mathrm{Cp} 2 \mathrm{Mg}$. The use of the latter magnesium complex for the synthesis of ferrocene etc4 is a very specific type of transmetallation, a metallocene to metallocene conversion where the two complexes are based on a different metal.5 Other examples of this type of transformation appear to be rare,6-8 in particular, the transformation of one air, moisture and thermally stable d-block based complex into another. 9 In this communication we describe the conversion of substituted ferrocene derivatives into substituted iridocenium cations, 10 reactions that proceed via the intermediacy of planar chiral iridacycles.

We recently reported that reaction of ferrocenyloxazoline 1 with $\left[\mathrm{Cp}^{*} \mid \mathrm{ICl} 2\right] 2$ in acetonitrile with 4 equivalents of KPF6 and 4 equivalents of $\mathrm{NaOH}$ results in the formation of a single diastereoisomer of neutral iridacycle 2 containing a cyanomethy ligand (Scheme 1$) \cdot{ }^{11}$

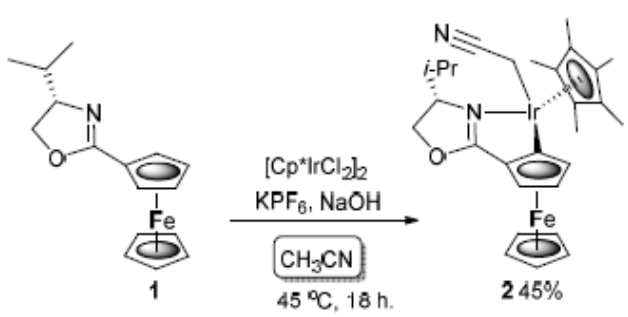

Scheme 1 Highly diastereoselective synthesis of planar chiral and chiral-at-metal iridacycle $2 .{ }^{11}$

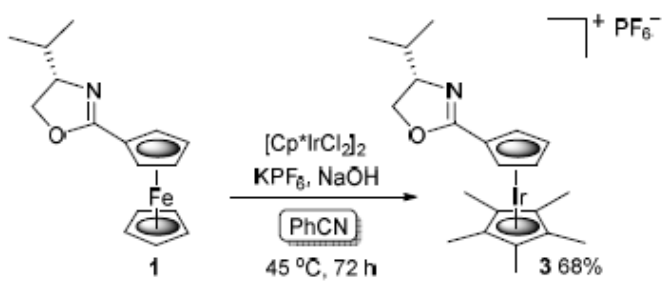

Scheme 2 Conversion of ferreocenyloxazoline 1 into oxazolinesubstituted iridocenium complex $\mathbf{3}$. 
In an attempt to generate a corresponding nitrile-ligated cationic iridacycle, benzonitrile was employed as the reaction solvent to avoid the deprotonation and rearrangement of acetonitrile that results in the formation of 2 . With 2 equivalents of $\mathrm{NaOH}$ this reaction resulted in the isolation of an air and thermally stable new complex, for which the $1 \mathrm{H}$ NMR spectrum contained four diastereotopiccyclopentadienyl hydrogen signals at significantly higher chemical shift than would be expected for a ferrocene derivative $\left(5.77,5.79,5.84\right.$ and $5.88 \mathrm{ppm}$ in $\left.\mathrm{CDCl}_{3}\right)$. In addition to signals from the oxazoline moiety, the spectrum contained a $\mathrm{Cp}^{*}$ singlet at $2.16 \mathrm{ppm}$ with a relative integration of fifteen. The identity of the product as hexafluorophosphate iridocenium salt $\mathbf{3}$ was confirmed by X-ray crystallography (Figure 1).12 Replacement of benzonitrile by trimethylacetonitrile also resulted in the generation of $3(47 \%)$. No reaction occurred when $[\mathrm{Cp} * \mathrm{IrCl} 2] 2$ was replaced by $[\mathrm{Cp} * \mathrm{RhCl}] 2$ or $[\mathrm{Ru}(\mathrm{p}$-cymene) $\mathrm{Cl} 2] 2$ with benzonitrile as solvent under the same conditions that gave 3 .

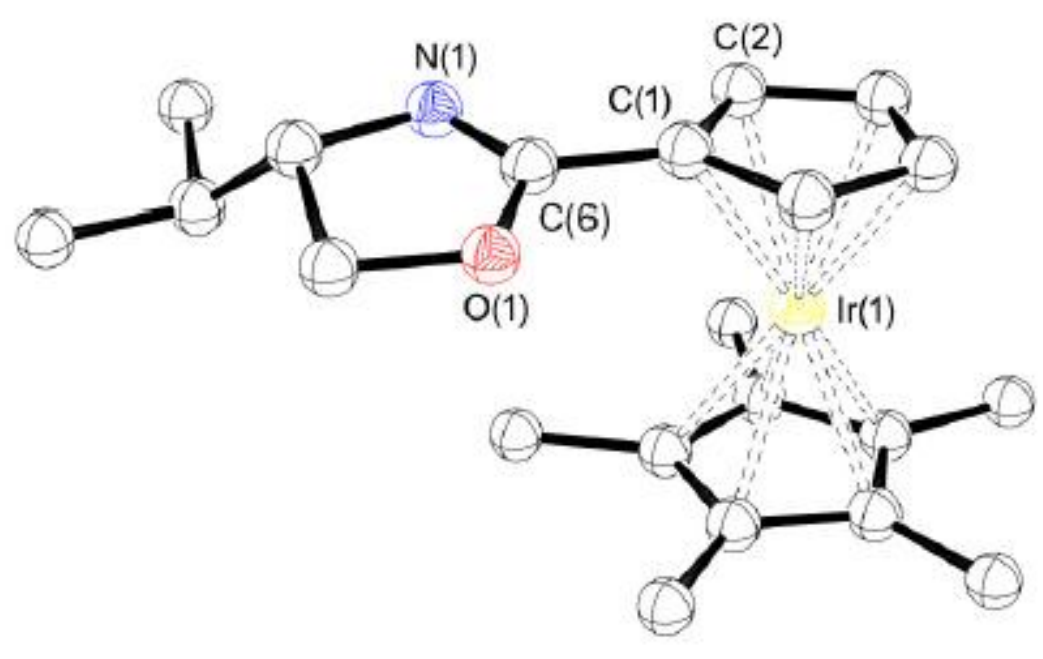

Fig. 1 A representation of the X-ray structure of 3 (hydrogen atoms, disordered atoms ( $\mathrm{Cp}$ * and $\mathrm{Ir}$ ) and hexafluorophosphate ion omitted for clarity). Principle bond lengths $[\AA]$ include: $\operatorname{lr}(1)-\mathrm{Cp} *$ (centre of mass) $=1.817(3), \operatorname{Ir}(1)-C p$ (centre of mass) $=1.813(3), C(1)-C(6)=1.455(12), C(6)-O(1)=$ 1.350(9), $C(6)-N(1)=1.272(11)$. Principle torsion angles $\left({ }^{\circ}\right)$ include: $C(2)-C(1)-C(6)-N(1)=-11.8(13)$.

The cationic iridacycle 4, containing a coordinated acetonitrile ligand, is available from 1 by a reduction in the quantity of base employed (either $\mathrm{NaOH}$ or $\mathrm{KOtBu}$ ) to one equivalent on reaction with [Cp*IrCl2]2 and KPF6 for 18 hours (Scheme 3).11 Re- examination of the synthesis of 4 employing $\mathrm{NaOH}$ as base, with an increase in the reaction time to $24 \mathrm{~h}$ at $45 \mathrm{oC}$, revealed a $5: 1$ ratio of $4: 3$ following work-up.13 With a 5 day reaction time the ratio of $4: 3$ was $1: 1$.

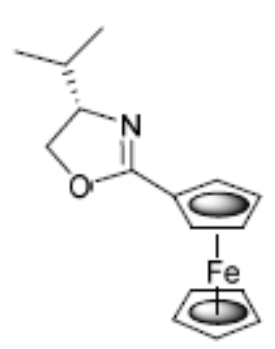

1

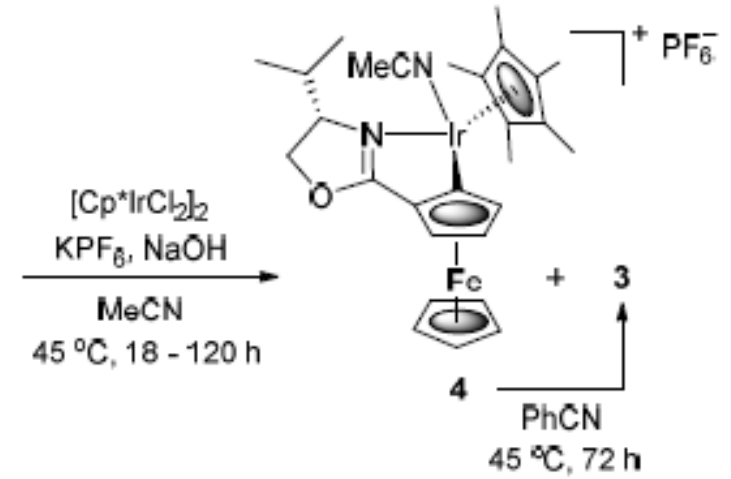


Scheme 3 Synthesis of cationic iridacycle 4 and iridocenium cation 3.

These results point to cationic iridacycle 4 being a precursor to iridocenium 3, a hypothesis supported by the clean conversion of 4 into 3 on heating at $45 \mathrm{oC}$ in benzonitrile for 3 days. Following isolation, a solution of 4 is stable in CD3CN under argon, but heating to $45 \mathrm{oC}$ in this instance resulted only in decomposition.

Two further results support the intermediacy of a cationic iridacycle in iridocenium formation. Firstly, reaction of methyl ferrocenecarboxylate with $\left[\mathrm{Cp}^{*} \mid \mathrm{ICl} 2\right] 2$ under the same conditions as given in Scheme 2 resulted only in the recovery of the starting ester.

Thus a substrate that is less able to coordinate to iridium, and by extension not able to form an iridacycle, does not result in iridocenium formation. Secondly, and in contrast to the stability of neutral imine-based iridacycle 5,11 the cationic complex that results from chloride abstraction with AgPF6 transformed over a period of 1 day into iridoceniumcarbaldehyde 6 (Scheme 4). This complex was identified, in part, by the $1[9.79(\mathrm{~s})]: 2(6.01(\mathrm{t}, \mathrm{J}, 2.0)]: 2[5.76(\mathrm{t}, \mathrm{J}, 2.0)]: 15[1.57(\mathrm{~s})]$ ratio of signals in the $1 \mathrm{H}$ NMR spectrum (CD3CN), the aldehyde moiety arising from facile aldimine hydrolysis under the conditions used for product isolation.
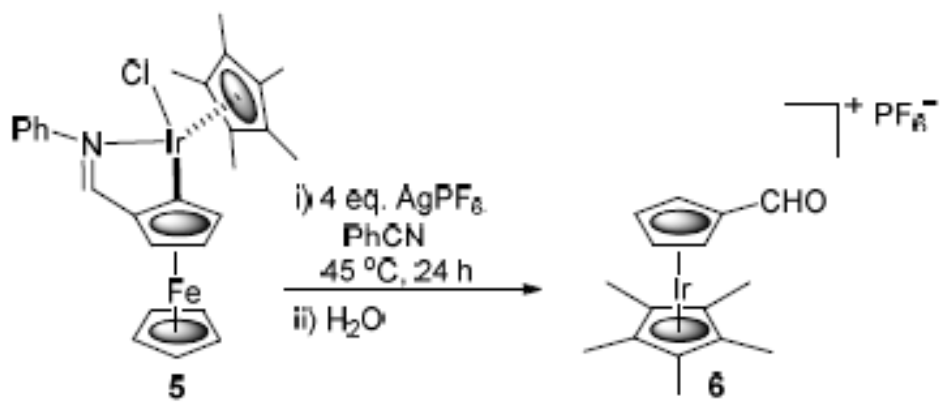

Scheme 4 Synthesis of iridoceniumcarbaldehyde 6

We next investigated the stereochemistry of the ferrocene-iridocenium transformation with planar chiral ( $\mathrm{S}, \mathrm{Rp})-7$ synthesised by highly diastereoselective lithiation 14 and addition of Mel.15 This was transformed into iridocenium complexes $(\mathrm{S}, \mathrm{Rp})-8$ and $(\mathrm{S}, \mathrm{Sp})-8$ as a 1:0.86 ratio of diastereoisomers (assignment impossible), this ratio not changing during the course of the reaction (Scheme 5 ). The same outcome was observed starting with a $(\mathrm{S}, \mathrm{Rp})-7 /(\mathrm{S}, \mathrm{Sp})-7$ ratio of 2:1. Thus this iridocenium formation reaction is not stereospecific with respect to planar chirality, and shows little stereoselectivity.

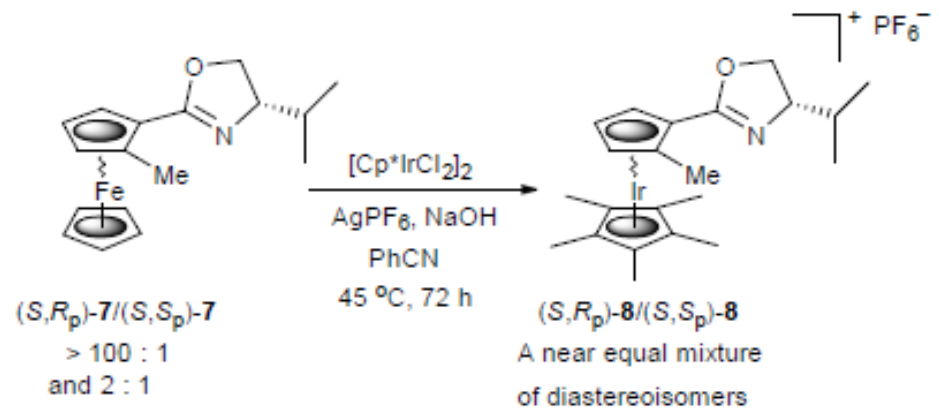

Scheme 5 Investigation into the planar chiral stereochemistry of substituted ferrocene to substituted iridocenium conversion. 


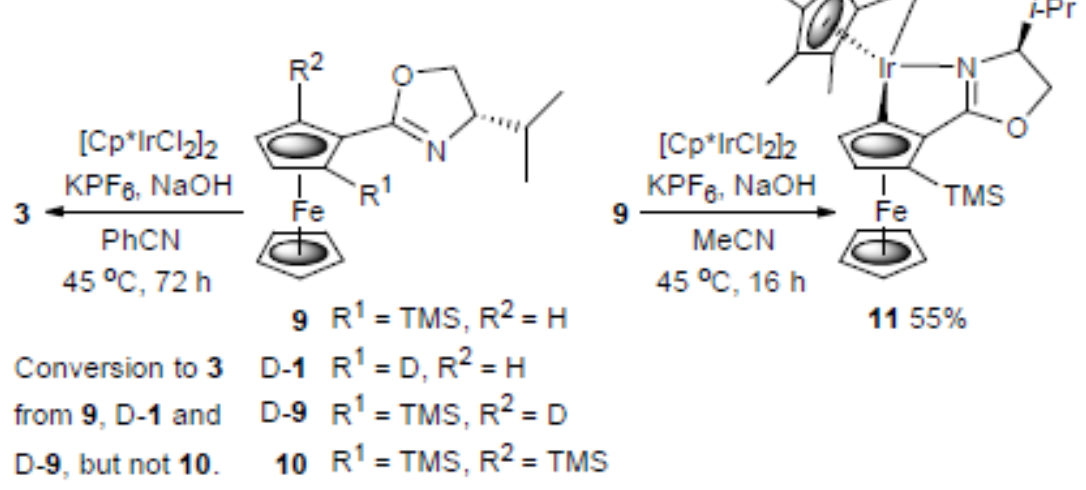

Scheme 6 Generation of iridocenium 3 from trimethylsilylated and deuterated precursors, and retention of TMS on iridacycle formation.

Application of the iridocenium synthesis protocol to diastereomerically pure 916 containing a TMS substituent resulted in desilylation and isolation of 3 (Scheme 6). The same outcome was observed with deuterated D-1 and trimethylsilyl/deuterated D-9. In contrast, doubly silylated 10 was recovered unchanged from the reaction. That desilylation of 9 does not occur on iridacycle formation had been determined previously with the isolation of 11,11 hydrogen/deuterium shifts. When the partially deuterated product obtained from run 2 (Table 1) was heated at 45 oC for $48 \mathrm{~h}$ in benzonitrile with $\mathrm{D} 2 \mathrm{O}$, and no NaOD, no change was observed in the $1 \mathrm{H}$ NMR of the material isolated. This reveals the requirement of deuteroxide in deuterium incorporation, and by extension the role of hydroxide or deuteroxide in iridocenium formation the TMS blocking group resulting in the opposite sense of planar chirality. The absence of reaction with 10 is consistent with the two blocking groups preventing iridacycle formation, and thus generation of an iridocenium cation.

Deuterium incorporation during iridocenium complex formation was investigated by replacement of $\mathrm{NaOH}$ with 20 eq. of $\mathrm{NaOD}$ (as a 40\% wt. solution in D2O - Scheme 7, Table 1, entry 1). This resulted in the formation of 3 with partial deuterium incorporation into the cyclopentadienyl and pentamethylcyclopentadienyl moieties, and no incorporation into the oxazoline. Starting material 1 recovered from this reaction contained no incorporated deuterium. Iridocenium deuteration was also observed on addition of 10 eq. of $\mathrm{NaOD}$ in D2O to 3 and heating in benzonitrile at $45 \mathrm{oC}$ for $24 \mathrm{~h}$ (entry 2). On increasing this reaction time to $72 \mathrm{~h}$ further deuteration of the $\mathrm{Cp}$ and $\mathrm{Cp} *$ groups was observed (entry 3 ).

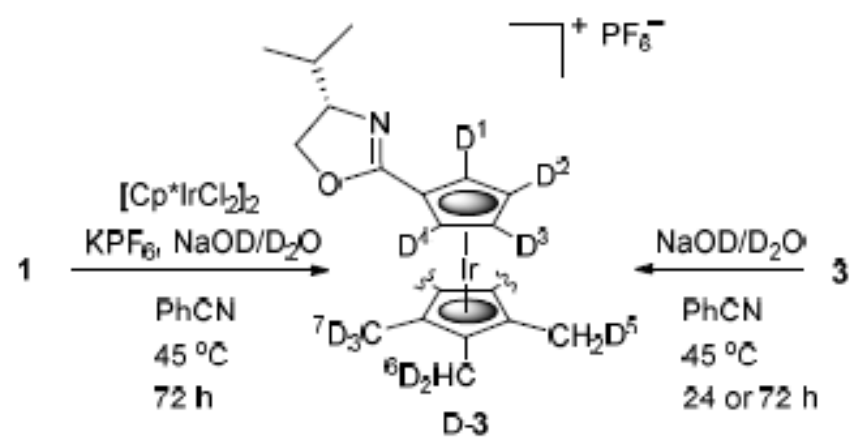

Scheme 7 Formation of deuterated 3. 
Table 1 Percentage deuterium incorporation into 3.a

\begin{tabular}{ccccccccc}
\hline Entry & $\mathrm{SM}^{\mathrm{b}}$ & ${ }^{\mathrm{c}} \mathrm{RT}$ & $\mathrm{D}^{1}$ & $\mathrm{D}^{2} / /^{3}$ & $\mathrm{D}^{4}$ & ${ }^{\mathrm{d}} \mathrm{D}^{5}$ & ${ }^{\mathrm{e}} \mathrm{D}^{6}$ & ${ }^{\mathrm{f}} \mathrm{D}^{7}$ \\
\hline $\mathbf{1}$ & $\mathbf{1}$ & $72 \mathrm{~h}$ & 43 & 13 & 39 & 41 & 40 & 6 \\
2 & $\mathbf{3}$ & $24 \mathrm{~h}$ & 66 & 19 & 58 & 40 & 32 & 15 \\
3 & $\mathbf{3}$ & $72 \mathrm{~h}$ & 78 & 33 & 76 & 21 & 42 & 34 \\
\hline
\end{tabular}

${ }^{a}$ Determined by ${ }^{1}$ H NMR. ${ }^{b}$ Starting material. ${ }^{\text {c }}$ Reaction time. ${ }^{\mathrm{d}}$ From 1:1:1 triplet at $2.09 \mathrm{ppm}$. ${ }^{\mathrm{e}}$ From 1:2:3:2:1 pentet at $2.08 \mathrm{ppm}$.

${ }^{\mathrm{f}}$ Calculated from remaining singlet at $2.11 \mathrm{ppm}$.

Loss of the exchangeable ligand from iridacycles such as 4 and 5 results in coordinativelyunsaturated iridacycle 12 (Scheme 8). For the cation derived from 5 calculations give an iridium-iron bonding parameter of 1.25, and partial charge delocalisation onto iron.11 A possible mechanism for the loss of $\mathrm{CpFe}+$ is via migration of this moiety onto iridium, and iron ligation by the nitrile solvent and/or hydroxide/water.17 The resulting neutral and resonance-stabilised cyclopentadienyliridacycle can coordinate water to give 13 from which can occur reversible proto-deiridation.18 A related process may account for the desilylation of 9 . Subsequent loss of the hydroxide ligand from 14 , and non-facially selective $\eta 5$ - coordination, completes this suggested pathway for iridocenium formation. That deuterium incorporation was observed when iridocenium 3 was heated with NaOD in D2O points to the reversible formation of 13 . In addition to $\alpha$-deuteration with respect to the oxazoline substituent (D1 and D4), a lesser degree of $\beta$-deuteration was also observed (D2/3 - Table 1). Assuming that formation of a $\beta$ - analogue of 13 is not possible, this suggests the reversible formation of 15, from which scrambling can occur by [1,5]-hydrogen/deuterium shifts. When the partially deuterated product obtained from run 2 (Table 1) was heated at $45 \mathrm{oC}$ for $48 \mathrm{~h}$ in benzonitrile with $\mathrm{D} 2 \mathrm{O}$, and no NaOD, no change was observed in the $1 \mathrm{H}$ NMR of the material isolated. This reveals the requirement of deuteroxide in deuterium incorporation, and by extension the role of hydroxide or deuteroxide in iridocenium formation.
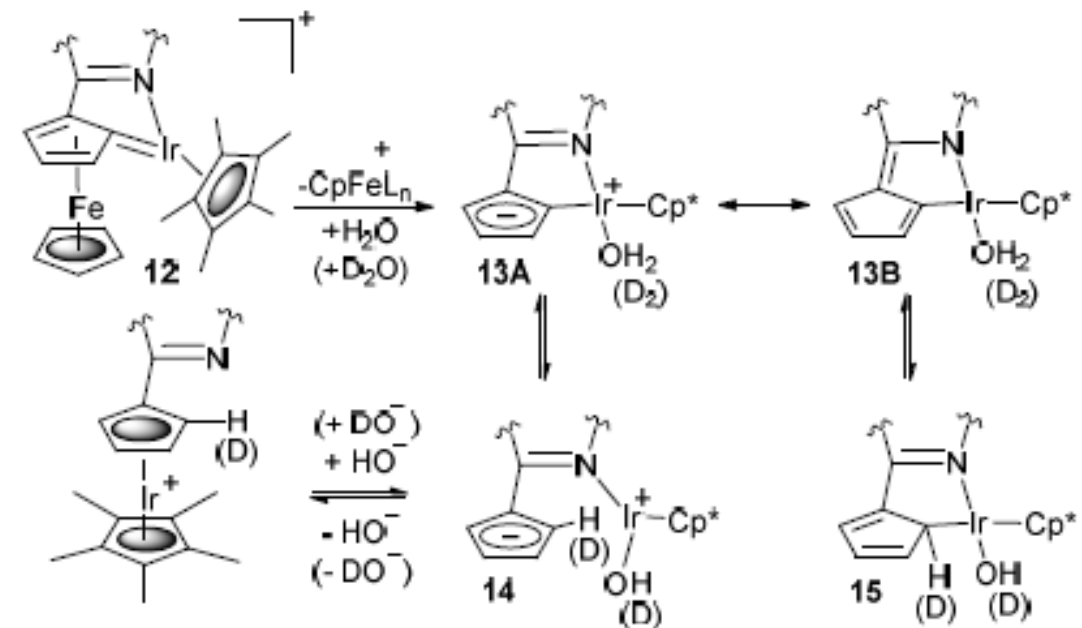

Scheme 8 Outline pathway for iridacycle to iridocenium conversion.

The intermediacy of an iridium-hydroxide species also accounts for deuterium incorporation into Cp*. First reported by Maitlis,19 a later study by Macchioni with [Cp*RhCl(PTA)2]X (PTA = 7phospha-1,3,5-triazaadamantane) revealed abstraction of a $\mathrm{Cp}^{*}$ methyl proton by a coordinated hydroxide anion.20 By extension, a generalised deuteroxide-iridium(III) coordinated intermediate 16 can reversibly generate $\operatorname{Ir}(\mathrm{I})$-fulvene 17 as the intermediate in the formation of D-16 (Scheme 9). 

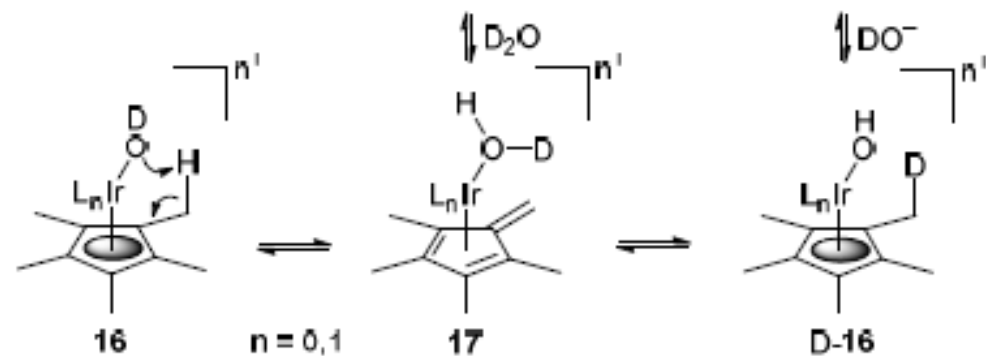

Scheme 9 Mechanism of $\mathrm{Cp}^{*}$ deuterium incorporation.

\section{Conclusions}

Heating an oxazoline-substituted ferrocene with $\left[\mathrm{Cp}^{*} \mid \mathrm{rCl} 2\right] 2$ in benzonitrile with $\mathrm{NaOH}$ and KPF6 results in the formation of an oxazoline-substituted pentamethyliridocenium cation. This transformation of one air, moisture and thermally stable d-block based metallocene previous precedent. A key intermediate in the kinetically accessible pathway is a cationic iridacycle. Deuterium incorporation with $\mathrm{NaOD} / \mathrm{D} 2 \mathrm{O}$ occurs at $\mathrm{Cp}^{*}$ and at the $\alpha / \beta$-cyclopentadienyl positions. These outcomes are compatible with the reversible formation of the pentamethyliridocenium product by $\eta 5$-cyclopentadienyl complexation from a deuteroxide coordinated iridium-Cp* complex. This first report on the synthesis of a chiral non- racemic iridocenium metallocene provides access to novel iridium-based species for future catalytic investigations.

The Al-Chem Channel (RAA) is thanked for financial support. We also thank the EPSRC National Mass Spectrometry Centre (University of Wales, Swansea). 


\section{Notes and references}

a School of Chemistry, Norwich Research Park, Norwich, NR4 7TU, U.K.

b EPSRC National Crystallography Service, School of Chemistry,

University of Southampton, Highfield, Southampton, SO17 1BJ, U.K.

$+\quad$ General procedure for the preparation of (n5-(S)-2-(4-(1-

methylethyl))oxazolinylcyclopentadienyl)(n5-pentamethylcyclopentadien- yl)iridium(III)

hexafluorophosphate. (S)-2-Ferrocenyl-4-(1- methylethyl)oxazoline (0.019 g, $0.06 \mathrm{mmol})$, (pentamethylcyclopenta- dienyl)iridium(III) chloride dimer (0.025 g, $0.03 \mathrm{mmol}), \mathrm{NaOH}(0.005 \mathrm{~g}$

$0.13 \mathrm{mmol})$ and potassium hexafluorophosphate $(0.047 \mathrm{~g}, 0.26 \mathrm{mmol})$ were added to a flame dried Schlenk tube under an inert atmosphere. After the addition of benzonitrile $(5 \mathrm{~mL})$ the mixture was stirred at $45^{\circ} \mathrm{C}$ for 3 days. Once cooled to room temperature hexane was added and the reaction mixture stirred vigourously for 5 mins. The resulting suspention was filtered through Celite using hexane as the eluent and the column flushed with hexane twice to remove any remaining benzonitrile. Once all the benzonitrile had been removed, acetonitrile was used to flush the brown precipitate from the top of the Celite, and the resulting solution was collected and concentrated in vacuo. Purification was achieved by filtration through a pad of neutral alumina, using acetonitrile as the eluent, and collecting the first bright yellow fractions (subsequent pale yellow fractions contained small amounts of starting material). Removal of the solvent in vacuo yielded the product as a mustard yellow crystalline solid (0.0278 g, 68\%): $\mathrm{mp} 189.7$ - $191.2^{\circ} \mathrm{C}$ (Found: $\mathrm{C}, 38.77 ; \mathrm{H}, 4.46$; $\mathrm{N}, 2.22$. C21H29F6IrNOP Requires C, 38.89; $\mathrm{H}, 4.51 ; \mathrm{N}, 2.16 \%), \mathrm{HRMS}$ (ES) [cation]+ $\mathrm{C} 21 \mathrm{H} 29$ IrNO+, Calc. 502.1850, Obs. $502.1843 ; 23.0^{\circ} \mathrm{C}=-41.8$ (c = 0.22, acetonitrile); $\mathrm{v}(\mathrm{film}) / \mathrm{cm}-1$ 2962, 2970, 1666 (C=N), 841; 1H NMR (500 MHz, CDCl3) 5.88 (1H, bs, Cp-H), 5.84 (1H, bs, Cp-H), $5.79(1 \mathrm{H}, \mathrm{bs}, \mathrm{Cp}-\mathrm{H}), 5.77(1 \mathrm{H}, \mathrm{bs}, \mathrm{Cp}-\mathrm{H}), 4.41(1 \mathrm{H}, \mathrm{dd}, \mathrm{J}=9.1,8.5 \mathrm{~Hz}, \mathrm{CHH}), 4.06(1 \mathrm{H}, \mathrm{t}, \mathrm{J}=8.5 \mathrm{~Hz}$, $\mathrm{CHH}), 4.03-3.97(1 \mathrm{H}, \mathrm{m}, \mathrm{CH}), 2.16\left(15 \mathrm{H}, \mathrm{s}, \mathrm{Cp}^{*}\right), 1.77-1.69(1 \mathrm{H}, \mathrm{m}, \mathrm{CH}(\mathrm{CH} 3) 2), 1.03(3 \mathrm{H}, \mathrm{d}, \mathrm{J}=6.7$ $\mathrm{Hz}, \mathrm{CH} 3), 0.92(3 \mathrm{H}, \mathrm{d}, \mathrm{J}=6.7 \mathrm{~Hz}, \mathrm{CH} 3) ; 13 \mathrm{C} \mathrm{NMR}(125 \mathrm{MHz}, \mathrm{CDCl} 3) \delta 157.02,95.84,84.79,83.22$, $83.12,80.74,80.64,73.61,71.43,33.46,19.28,18.69,10.05$.

Electronic Supplementary Information (ESI) available: Experimental methods and characterisation data. CCDC1442801 contains supplementary X-ray crystallographic data for 3 . This data can be obtained free of charge via http://www.ccdc.cam.ac.uk/conts/retrieving.html, or from the Cambridge Crystallographic Data Centre, Union Road, Cambridge, CB2 1EZ; fax (+44) 1223-336-033 or email: deposit@ccdc.cam.ac.uk.

1 (a) Ferrocenes: Homogeneous Catalysis, Organic Synthesis, Materials Science, ed. A. Togni and T. Hayashi, Wiley-VCH, Weinheim, 1995. (b) Metallocenes: Synthesis, Reactivity, Applications, ed. A. Togni and R. L. Halterman, Wiley-VCH, Weinheim, 1998. (c) N. J. Long Metallocenes: An Introduction to Sandwich Complexes, Blackwell Science, Oxford, 1998. (d) R. C. J. Atkinson, V. C. Gibson and N. J. Long, Chem. Soc. Rev., 2004, 33, 313. (e) R. G. Arrayás, J. Adrio and J. C. Carretero, Angew. Chem. Int. Ed., 2006, 45, 7674. (f) D. Schaarschmidt and H. Lang, Organometallics, 2013, 32, 5668. 

1997, 540, 127. (b) S. McVey and P. L. Pauson, J. Chem. Soc., 1965, 4312. (c) J. C. Ruble, H. A. Latham and G. C. Fu, J. Am. Chem. Soc., 1997, 119, 1492.

$4 \quad$ A. F. Reid and P. C. Wailes, Aust. J. Chem., 1966, 19, 309.

5 A suggested term for his process is transmetallocenation, by extension of transmetallation and by analogy to transesterification, transamidation etc.

6 Addition of aluminium chloride to decamethylsilicocene results in another $\mathrm{p}$-block metallocene, decamethylaluminocenium tetrachloroaluminate. U. Holtmann, P. Jutzi, T. Kühler, B. Neumann and H.-G. Stammler, Organometallics, 1999, 18, 5531.

7 The reaction between dicyclopentadienyl mercury with activated lanthanide elements is a route to divalent lanthanide cyclopentadienyl complexes. G. Z. Suleimanov, L. F. Rybakova, Ya.A. Nuriev, T. Kh. Kurbanoz and I. P. Beletskaya, J. Organomet. Chem., 1982, 235, C19.

8 Metathesis of bis(n5-2,5-di-tert-butylphospholyl)lead with [MCp*X2]2 ( $\mathrm{M}=\mathrm{Co}, \mathrm{Rh}, \mathrm{Ir}$ ) gives monophosphametallocenium cations. K. Forissier, L. Ricard, D. Carmichael and F. Mathey, Organometallics, 2000, 19, 954.

9 Radioactive metallocenes incorporating 59Fe, 103Ru and 1910s have been generated from simple ferrocene derivatives by heating at high temperature with radioactive metal halides. See: (a) D. Langheim, M. Wenzel and E. Nipper, Chem. Ber., 1975, 108, 146. (b) E. A. Stadlbauer, E. Nipper and M. Wenzel, J. Labelled Comp. Radiopharm., 1977, 13, 491.

10 There are a small number of reports on the synthesis of iridocenium cations, see: (a) $\mathrm{K}$. Moseley, J. W. Kang and P. M. Maitlis, J. Chem. Soc. A, 1970, 2875. (b) P. L. Holland, R. A. Andersen and R. G. Bergman, Organometallics, 1998, 17, 433. (c) O. V. Gusev, L. N. Morozova, T. A. Peganova, P. V. Petrovskii, N. A. Ustynyuk and P.M. Maitlis, J. Organomet. Chem., 1994, 472, 359. (d) Yu. T. Struchkov, M. Yu. Antipin, K. A. Lyssenko, O. V. Gusev, T. A. Peganova, N. A. Ustynyuk, J. Organomet. Chem., 1997, 536-537, 281. (e) S. K. Mohapatra, A. Romanov, G. Angles, T. V. Timofeeva, S. Barlow, S. R. Marder, J. Organomet. Chem., 2012, 706-707, 140.

11 R. A. Arthurs, M. Ismail, C. C. Prior, V. S. Oganesyan, P. N. Horton, S. J. Coles and C. J. Richards, Chem. Eur. J., 2016, 22, 3065.

12 Crystal data for 3: C21H29F6IrNOP,M $=648.62$, pale yellow needle, $a=7.0929(2), b=$ 15.6774(4), $c=20.8647(5) \AA, V=2320.12(10) \AA 3, T=100(2) K$, space group P212121, $Z=4, \mu=1.857$ $\mathrm{mm}$, reflections collected $=15356$, independent reflections $=5262$, Rint $=0.0298$, Flack parameter $=$ $-0.007(6), \mathrm{R} 1=0.0281, \mathrm{WR2}=0.0590$ [F2 $>2$ ] (F2)], R1 $=0.0333, \mathrm{WR2}=0.0606$ (all data). There is disorder of the $\mathrm{Cp}^{*}$ and hexafluorophosphate ion. For this various geometrical (SAME) and displacement (RIGU) restraints have been used. The $\mathrm{Cp}$ and $\mathrm{Cp}$ * rings form infinite alternating stacks. A small percentage (about $2.5 \%$ ) effectively stack in the opposite direction with the Ir ion lying in the gap. Although it is offset, only the second Ir ion is modelled.

13 Complex 4 was isolated previously by chromatography on neutral Al2O3 with acetonitrile as the elutent.11 The ratio of 4 to 3 was determined by $1 \mathrm{H}$ NMR following non-separative filtration through neutral Al2O3.

14 T. Sammakia and H. A. Latham, J. Org. Chem., 1995, 60, 6002. 
15 Y. Nishibayashi, K. Segawa, Y. Arikawa, K, Ohe, M. Hidai and S. Uemura, J. Organomet. Chem., 1997, 545-546, 381.

16 C. J. Richards and A. W. Mulvaney, Tetrahedron: Asymmetry, 1996, 7, 1419.

17 D. C. Boyd, D. A. Bohling and K. R. Mann, J. Am. Chem. Soc., 1985, 107, 1641.

18 (a) W. J. Tenn, III, K. J. H. Young, J. Oxgaard, R. J. Nielsen, W. A. Goddard, III, and R. A. Periana, Organometallics, 2006, 25, 5173. (b) J. Oxgaard, W. J. Tenn, III, R. J. Nielsen, R. A. Periana and W. A. Goddard, III, Organometallics, 2007, 26, 1565.

19 J. W. Kang and P. M. Maitlis, J. Organomet. Chem., 1971, 30, 127.

20 G. Ciancaleoni, S. Bolaño, J. Bravo, M. Peruzzini, L. Gonsalvi and A. Macchioni, Dalton Trans., 2010, 39, 3366. 